\title{
A heterotopia dos museus brasileiros e os deslocamentos da Modernidade
}

\author{
Rodrigo R. H. F. Valverde ${ }^{1}$
}

Resumo: Como a noção de heterotopia de Foucault pode nos servir para avaliar os conflitos observados nos museus brasileiros durante o início do século XXI? Esta é a pergunta que anima este artigo: as territorialidades que se manifestam atualmente nos museus pressionam a organização de suas exposições, o tempo de exibição e a visibilidade de seus artistas. Mitchell classifica esse uso da cultura como próprio a uma guerra cultural, no qual as expressões dos grupos de interesse se projetam para além do sentido artístico do debate, com claras intenções de projeção política. Ainda que os limites entre política, ciência e arte não possam ser definidos com facilidade e que, via de regra, não há fenômeno dissociado da esfera política, os museus não foram normatizados ou organizados para mediar e sediar os conflitos políticos. Nesse deslocamento da política em uma fase avançada da Modernidade, pode ser observado uma tentativa de rearranjo de forças que só ganham sentido quando associado à organização do espaço.

Palavras-chaves: heterotopia; museu; territorialidade; Modernidade.

\section{La heterotopía de los museos brasileños y los desplazamientos de la Modernidad}

Resumen: ¿Cómo nos puede servir la noción de heterotopía de Foucault para evaluar los conflictos observados en los museos brasileños a principios del siglo XXI? Esta es la pregunta que anima este artículo: las territorialidades que se manifiestan actualmente en los museos ejercen presión sobre la organización de sus exposiciones, el tiempo de exposición y la visibilidad de sus artistas. Mitchell clasifica este uso de la cultura como propio de una guerra cultural, en la que las expresiones de los grupos de interés se proyectan más allá del sentido artístico del debate, con claras intenciones de proyección política. Aunque los límites entre política, ciencia y arte no puedan definirse fácilmente y, por regla general, no existe un fenómeno disociado de la esfera política, los museos no han sido estandarizados u organizados para mediar y recibir conflictos políticos. En este desplazamiento de la política en una fase avanzada de la Modernidad, se puede observar un intento de reorganizar las fuerzas que solo tienen sentido cuando se asocian con la organización del espacio.

Palabras clave: heterotopia; museo; territorialidad; Modernidad.

\section{The heterotopia of Brazilian museums and the displacements of Modernity}

\begin{abstract}
How can Foucault's notion of heterotopia serve us to evaluate conflicts observed in Brazilian museums in the 21 st century? This is the question that stimulates this article: the territorialities that are currently manifested in museums put pressure on the organization of their exhibitions, the exhibition period and the visibility of their artists. Mitchell classifies this use of culture as proper to a cultural war, in which the expressions of interest groups project beyond the artistic sense of the debate, with clear intentions of political effect. Although the boundaries between politics, science and art cannot be easily defined and, as a rule, there is no phenomena dissociated from the political sphere, museums have not been standardized or organized to mediate and host political conflicts. In this displacement of politics in an advanced phase of Modernity, an attempt to rearrange forces that only make sense when associated with the organization of space can be observed.
\end{abstract}

Keywords: heterotopia; museum; territoriality; Modernity.

\section{$(i) \$$}

DOI: https://doi.org/10.26512/patryter.v3i5.27267

Como citar este artigo: Valverde, R. R. H. F. (2020). A heterotopia dos museus brasileiros e os deslocamentos da Modernidade. PatryTer - Revista Latinoamericana e Caribenha de Geografia e Humanidades, 3 (5), 14-29. DOI: https://doi.org/10.26512/patryter.v3i5.27267

Recebido: 24 de setembro de 2019. Aceite: 11 de dezembro de 2019. Publicado: 01 de março de 2020. ${ }^{1}$ Professor do Departamento de Geografia da Universidade de São Paulo. ORCID: https://orcid.org/0000-00022212-9871. E-mail: rvalverde@usp.br. 


\section{Introdução}

O Instituto Brasileiro de Museus (IBRAM), órgão público criado em 2009 e desmembrado do Instituto do Patrimônio Histórico e Artístico Nacional (IPHAN), é o responsável na atualidade pelo desenvolvimento da Política Nacional de Museus (PNM), além de ser o administrador direto de 30 museus federais. Por definição, o IBRAM apresenta os museus como espaços que:

Assume(m) funções as mais diversas e envolventes. Uma vontade de memória seduz as pessoas e as condur à procura de registros antigos e novos, levando-as ao campo dos museus, no qual as portas se abrem sempre mais. A museologia é hoje compartilhada como uma prática a serviço da vida. O museu é o lugar em que sensações, ideias e imagens de pronto irradiadas por objetos $e$ referenciais ali reunidos iluminam valores essenciais para o ser bumano. Espaço fascinante onde se descobre e se aprende, nele se amplia o conbecimento $e$ se aprofunda a consciência da identidade, da solidariedade e da partilha. Por meio dos museus, a vida social recupera a dimensão humana que se esvai na pressa da hora. As cidades encontram o espelho que lhes revele a face apagada no turbilhão do cotidiano. E cada pessoa acolhida por um museu acaba por saber mais de si mesma. (IBRAM, 2019).

No entanto, o espaço museal já passou por diversos projetos para gerar diferentes inspirações, com vários agentes, arranjos, financiadores e objetivos. Por exemplo, de modo diferente do que era observado em 1946, quando da fundação do International Council of Museums (ICOM), a situação observada parecia ser distinta da atual, pois os Estados-Nação investiam então em políticas culturais como forma de ampliação de suas forças de coesão social. Esta discussão parece particularmente interessante na medida em que os museus ganharam destaque recentemente no Brasil como ambientes em risco de desaparecimento, seja pela deterioração do seu espaço físico, seja pelo questionamento do seu sentido público. Seus espaços têm sido apropriados por diferentes tipos de manifestações, diretas e indiretas, nas quais se discute simultaneamente estética, identidade e políticas públicas. O caráter crítico e por vezes violento destas manifestações tem colocado em questão o museu, sob bases éticas, morais e financeiras ${ }^{i}$.

O objetivo desta apresentação é analisar os desafios dos espaços museais brasileiros nos últimos 5 anos a partir da noção de heterotopia tal qual esta foi apresentada por Foucault (2001).
Foucault considerava que as heterotopias seriam localizações que: "possuem a curiosa propriedade de estar em relação com todos os outros lugares, mas de um modo tal que eles suspendem, neutralizam ou invertem o conjunto de relações que se acham designados e refletidos por eles" (Foucault, 2001, p. 1574). O autor sugeria que estes espaços constituiriam um corte no ritmo do cotidiano e da normalidade, desconstruindo simultaneamente o indivíduo e a sociedade, mas que seria mantido devido ao saciamento de uma determinada necessidade.

Quando Foucault abordava uma heterotopia dos museus, fazia apelo a esta localidade na qual diferentes tempos se acumulavam em uma mesma parte do mundo, articulando-os de modo problemático. As coleções que animavam os museus nos seus primórdios causariam estranhamentos aqueles que a vivenciariam, ainda que o caráter colonialista da coleção limitasse e classificasse os impactos da diversidade do mundo. Foucault argumentava que tal acumulação revelava um duplo caráter heterotópico na medida em que expunha o esforço total e classificatório próprio à Modernidade ao mesmo tempo em que causava o desconforto do deslocamento do indivíduo centrado e de sua racionalidade. Em suas palavras:

(...) Museus e bibliotecas são heterotopias nas quais o tempo não cessa de acumular e de se encarapitar no cume de si mesmo, enquanto no século XVII, até o fim do século XVIII ainda, os museus $e$ as bibliotecas eram a expressão de uma escolha individual. Em compensação, a ideia de tudo acumular, a ideia de constituir uma espécie de arquivo geral, a vontade de encerrar em um lugar todos os tempos, todas as épocas, todas as formas, todos os gostos, a ideia de constituir um lugar de todos os tempos que esteja ele próprio fora do tempo, inacessivel à sua 'mordida', o projeto de organizar assim uma espécie de acumulação perpétua e infinita do tempo em um lugar que não mudaria, pois bem, tudo isso pertence à nossa modernidade (Foucault, 2001, p. 1578).

Para os fins de nossa discussão brasileira, os museus ilustrados por Foucault (2001) se tratavam de questões instigantes, mas relativamente controladas, em um sentido de heterotopia que parecia mais algo de simbólico ou metafórico do que propriamente uma ruptura efetiva dos laços sociais. O efeito da heterotopia do museu que foi apresentado por Foucault seria simbolizar e organizar relações de dominação, ao mesmo tempo em que alertava e instruía o seu público. Transpostos os limites do espaço museal, a normalidade seria restaurada pela recuperação do 
ritmo do cotidiano. As aberturas e fechamentos dos espaços museais brasileiros nos comunicam subversões e inversões que Foucault não tinha como antecipar: tais localidades ganharam recentemente um sentido de rompimento com entidades estatais, com o status quo, com uma identidade nacional e com um sentido público mais claro. Sugerimos realizar uma discussão em que as transformações dos espaços museais, de seus agentes, público e recursos, são simbólicas de mudanças que se projetam na sociedade brasileira. A configuração de um momento avançado do período da Modernidade parece nos levar a deslocar uma parte dos referenciais que balizam a nossa vida social.

Arriscamos ao associar sob uma mesma base analítica diferentes fenômenos que tomam lugar nos ambientes museais brasileiros: museus que pegaram fogo (Museu da Língua Brasileira, Museu Nacional); museus que foram interditados ou fechados (Museu do Ipiranga, Museu do Estado do Pará); museus que se tornaram palcos de manifestações políticas (Santander Cultural, Museu de Arte Moderna de São Paulo); museus que foram apropriados por exposições temporárias de cunho identitário/individual; museus que receberam e se ordenaram por mostras de circulação internacional. O argumento aqui colocado é que o tipo de heterotopia que havia consolidado os ambientes museais se encontra em transição, tornando estes diferentes fenômenos aspectos de um processo comum. O museu se mostraria em descompasso com mudanças observadas no Estado e na sociedade, demonstrando dificuldades em retomar a sua proeminência como instituição cultural.

A heterotopia tal qual foi proposta por Foucault (2001) viria associada ao cumprimento de uma função. A função não deve ser entendida necessariamente nos termos foucaultianos como parte de uma política pública, conduzida pelo Estado. É preciso lembrar que Foucault falava de um fenômeno marginal que seria capaz de induz a desconstrução da vida moderna. O referido autor ligava a função da heterotopia à necessidade que os corpos saciavam, ou seja, à força que reunia as pessoas naquela mesma área, para além da política formal ou da simples projeção identitária. Ainda segundo o seu pensamento, haveria dois tipos de heterotopologias, as utopias e as heterotopias. As primeiras seriam derivativas de uma localidade tão controlada, ordenada e classificada que suas organizações seriam verdadeiras denúncias da desordem e da ausência de sentido em todas as outras localidades. As segundas seriam localidades tão fragmentadas e disputadas que inverteriam ou desconstruiriam os sentidos coletivos da sociedade (história, indivíduo etc.). Sugerimos como hipótese que a heterotopia no Brasil dos museus seria característica da passagem de um quadro utópico para um quadro distópico no século XXI. Tal transição coloca em crise os espaços museais na medida em que o seu ordenamento parece lento e problemático diante de uma fragmentação e de uma visibilidade de seus arranjos que não eram comuns no passado.

Para investigá-la, realizaremos uma investigação de alguns arranjos do espaço museal, de seu público e sentidos da arte, em conexão com os períodos históricos de referência. Com particular ênfase, debateremos os papéis cumpridos pelos museus ao longo da modernidade brasileira a partir da gestão e do planejamento das suas funções cumpridas. Por último, discutiremos o processo de desconstrução dos ambientes museais e do questionamento da sua (i)moralidade, na qual a redefinação (ou desaparecimento) dos seus espaços é tratada como parte da transformação da sociedade. Nos termos da guerra cultural discutida por Mitchell (2000), a organização e o sentido do museu nos levam a questionar os fundamentos da vida social brasileira (Valverde, 2019).

\section{Pressupostos histórico-geográficos da organização e do caráter público dos museus}

Faz-se necessário nesse momento destacar certos arranjos entre política, arte e organização espacial que conferiram diferentes sentidos ao museu ao longo de sua história. Não se trata aqui de um esforço de construção de arranjos sucessivos, dispostos em uma lógica evolutiva clara. Preferimos destacar que as formas de organização de museus possuem certos modelos ou maior conexão com certos tipos de práticas em cada período histórico, sem, com isso, pretendermos esgotar a historiografia dos museus ou sugerir a exclusividade de um modelo em cada período. Antes de avaliarmos diretamente a crise dos museus no Brasil, caberia enunciar estes modelos como pressupostos históricos-geográficos para compreender o arranjo heterotópico atual, como modo de introdução à superposição de camadas de organização espacial e de funções. Escolhemos analisar brevemente o Museu de Alexandria, o Palácio de Latrão e a Galeria dos Escritórios antes de tratar de modelos próprios à Modernidade, como o Museu do Homem de Paris.

A origem etimológica da palavra museu deriva da Antigüidade Grega, associada às Musas (História, Astronomia, Poesia, Dança, Teatro, Agricultura etc.), deidades consagradas à inspiração científica e artística nos limites das concepções 
destes dois campos nos séculos 3 e 2 a.C. De acordo com os registros mais frequentes, o Museu e a Biblioteca de Alexandria, criados por Ptolomeu I Soter, teriam sido os primeiros espaços a receberem uma tal denominação, ainda que certas coleções privadas neobabilônicas sejam antecedentes. Uma primeira característica do Museu de Alexandria que pode ser evocada era dessa co-presença entre metafísica e ciência, sem maior distinção de funções: de acordo com o registro da passagem de Estrabão por Alexandria, um clérigo era designado pelo rei para gerir a dupla função deste espaço. A descrição de sua organização física foi realizada por Marcus Vitruvius como composto de um passeio, uma êxedra e um santuário às Musas, contando com espaços de debates e reuniões. Os estudiosos que animavam as atividades do Museu de Alexandria eram descritos como pertencentes à instituição, no sentido de posse e não apenas de uso de suas habilidades e residiam nos limites do palácio anexo ao Museu. A vida privada destes estudiosos se confundia com a própria tarefa pública que desenvolviam e seu sustento era provido pelo rei. O espaço do Museu era aberto aos viajantes instruídos, àqueles que buscavam conhecimento, assim como estimulava a permanência deles nesse espaço. Se há um sentido maior no Museu de Alexandria, era o acúmulo de um conhecimento total (nos limites do que era tratado como conhecimento), acumulativo, transcendente e reunindo em uma mesma base os limites científicos e religiosos. Suas descobertas eram mobilizadas em decisões da política grega, restrita àqueles senhores de terra que não precisavam lutar pela sua sobrevivência, e ganhavam visibilidade nos embates entre os homens públicos da Antiguidade.

Por sua vez, observamos que o Palácio de Latrão, localizado no Vaticano, construção consagrada à administração pública na Antiguidade Romana, ganha novos sentidos a partir da sua definição como residência papal, a partir do ano de 313. As coleções de objetos artísticos, científicos e religiosos estabelecidas pela Igreja Católica no Palácio de Latrão foram praticamente inacessíveis ao público até o século XVI. Tais objetos eram vistos ou como parte de um conhecimento total da mentalidade católica que deveria ser manuseada apenas por aqueles que tivessem a capacidade de alcançar a correta interpretação ou então como um conhecimento herético, estranho e que deveria ser excluído do domínio público, sendo resguardados somente para contato de altos clérigos capazes de compreender, catalogar e diminuir o sentido imoral desses livros, estátuas etc. Durante as diferentes fases da Idade Média, a expansão da Igreja Católica veio acompanhada da absorção ou marginalização de outros sistemas religiosos e culturais, mantendo um conjunto de objetos como registros do seu papel de vigilância e purificação do mundo. Esta coleção se construía como algo de posse privada e os efeitos públicos dessa coleção eram vistas quase que exclusivamente pela negatividade: suas exibições eram proibidas e o contato ou posse de outros destes objetos eram tratados como atos criminais. Os passeios e átrios e a publicidade da coleção só são construídos após as crises da Igreja Católica e o incêndio do Palácio no final da Idade Média. Ainda assim, a abertura foi gradual quanto aos objetos e seletiva sobre o acesso público até o século XIX. O sentido do controle da visibilidade relativa à diversidade religiosa e cultural foi dominante durante quase a totalidade de sua história.

A Galeria dos Escritórios, estabelecida em Florença no ano de 1581 a partir da regência do Duque Francisco I de Médici, tinha sido criada inicialmente como um local para o exercício da atividade jurídica dos magistrados da cidade. Esta havia sido projetada em área contígua ao Palácio Vecchio, sede do ducado de Florença, para que o poder judiciário estivesse física e simbolicamente mais próximo das decisões e do olhar vigilante do Duque da cidade. À época, o poder político estava vinculado à hereditariedade dos Médici, que comandavam o Grão-Ducado a partir de 1532. Desde os seus primórdios, a Galeria dos Escritórios era ilustrada por afrescos com temas religiosos, sendo muitos dominados por personagens demoníacos ou monstruosos, fato que justificava o uso do termo grotesco para suas ilustrações. A ambiência era dominada pela intimidação dos magistrados em um Grão-Ducado recente como o de Florença, com exceção do último andar, no qual se abria uma galeria de esculturas romanas e pinturas da coleção privada de Francisco I de Médici. Apenas seus cortesãos teriam acesso a este espaço elitizado, que simbolizava seus novos domínios. O sentido da galeria era cumprir a dupla função de hierarquizar simbolicamente a sociedade ao mesmo tempo em que reforçava o status político da família. A arte (e o museu) era vista como positiva, como prova de erudição e de poder, mesmo aquela considerada imoral diante dos parâmetros da Igreja. Seu público ainda era limitado, assim como o debate de suas contribuições.

Tais modelos não podem ser usados como síntese de todas as experiências museais anteriores à Modernidade. No entanto, servem como referências de um alcance muito distinto da arte em relação ao que se define a partir do século XIX. De fato, a consolidação do Estado-Nação e o processo de secularização a ele vinculado representavam 
todo um novo campo de possibilidades para a política, para a ciência e para a cultura. Até este período, as normas e ritos da política não permitiam nem ao menos teoricamente o alcance de todos, a cultura e a identidade eram aspectos menores e limitados territorialmente e a ciência não configurava a força discursiva e justificadora que possui na atualidade. A Modernidade é o período no qual o arranjo de forças que conhecemos se configura: para romper o ordenamento do poder anterior, a Modernidade passa a ser organizada sob um apelo geral ao que é novo, ao rompimento das tradições. Esta nova ordem se funda nos limites de uma concepção científica e no desenho de um sistema republicano. Não havia, nos primeiros momentos do século XIX, a intenção de construir uma sociedade igualitária ou um poder acessível a todos. A ideia de seus primeiros defensores parecia vir vinculada à ascensão de extratos da burguesia industrial e comercial frente a um poder que não tinham acesso diretamente até então.

No entanto, se não seria a hereditariedade nobre, a defesa da moralidade religiosa ou a estabilidade de um sistema social tradicional que animariam o Estado-Nação republicano, abriam-se brechas nas cartas constitucionais para novos agentes e novas formas de legitimação do poder. A efervescência política do século XIX levava à prova as suas novas instituições, em esforços contínuos de atualização dos seus fundamentos para evitar a pressão de movimentos trabalhistas e sociais em geral. De acordo com Harvey (2008), o sentido revolucionário da Modernidade foi contido a duras penas ao longo do século XIX. Somavam-se aos aparelhos repressivos do Estado (Exército permanente, forças policiais numerosas) todo um novo conjunto de mecanismos que tinham na concepção de cultura um dos seus alicerces. Harvey (2008) argumenta que a pacificação promovida pelo Estado-Nação dependeu de um esforço em criar a coesão social que parecia desfeita com o rompimento do Antigo Regime. Seria necessário criar uma nova memória social, independente da monarquia e da religião. Para tanto, o Estado assumia uma perspectiva de construção ou reforço da nacionalidade por intermédio de escolas, universidades e museus, entre outras instituições. As formas de dominação da Modernidade sugeriam a necessidade da elaboração de uma homogeneidade social que limitasse a instabilidade de um regime republicano frente aos conflitos de classe.

Os museus se proliferaram e se diversificaram em sentidos que, até então, eram desconhecidos. Chamava atenção o fato de que antigos espaços religiosos e que antigas propriedades privadas nobres passassem a receber a organização de museus no processo de consolidação das repúblicas. Foi este o caso do Palácio de São Cristóvão, no Rio de Janeiro, que passou a ser conhecido como Museu Nacional, e do Palácio do Louvre, residência real da monarquia francesa até a Revolução, quando se converte em um museu. Eram agora parte do Estado-Nação e, por conseguinte, matéria do debate da publicidade. Tornavam-se equipamentos acessíveis a todos os cidadãos: quando não eram gratuitos, possuíam ingressos subsidiados pelo Estado. As coleções privadas foram em grande parte estatizadas e ganharam clara função didática no processo educacional das massas. Em paralelo às ações do Estado, a imprensa, os artistas e o público em geral passam a interagir a polemizar com $O$ desenvolvimento daquelas formas artísticas ou científicas que eram expostas nos espaços museais. As coleções eram vistas como parte do patrimônio público e refletiam o poder e os papéis do Estado.

Um primeiro modelo que merece ser discutido a partir da forma da organização espacial dos museus no período histórico da Modernidade se refere ao seu uso didático e documental como reforço do poder do Estado-Nação. Referimo-nos a ideia de que os museus deveriam cumprir um papel de reificação da estrutura de dominação do Estado. Novos herois, datas festivas, valores, recursos e símbolos em geral do poder do Estado deveriam ser evocados sem, para tanto, fazer apelo à hereditariedade monárquica e à fé religiosa. Este museu tampouco deveria permitir um entendimento que reforçasse a instabilidade do sistema republicano, o conflito de classes ou sustentasse os levantes coloniais, que ainda representavam importância fundamental na sustentação econômica dos novos Estados. A instituição museal que se se tornava pública deveria então fazer inequívoco apelo ao poderio renovado do Estado, agora qualificado por uma nacionalidade, em sua coleção de objetos artísticos. Tais objetos comunicavam o sentido civilizatório do Estado. Parte importante de sua coleção derivava do imperialismo pelo saque de objetos de diferentes culturas, colocados lado a lado nas estantes e salas dos museus sem preocupação maior de uma contextualização sobre o significado destes objetos. Outras partes eram oriundas de uma arte documental, na qual a representação artística deveria fazer parte de um inventário público dos símbolos humanos, em uma clara política de memória que substituísse e/ou absorvesse a memória tradicional, regional, familiar e religiosa que marcava o Antigo Regime. Um caso marcante deste tipo de instituição, para além dos já citados Museu do Louvre e do Museu Nacional do Rio de Janeiro, seria o Musée de L'Homme (Museu 
do Homem), encontrado em Paris e fundado em 1937, "herdeiro" do Museu etnográfico do Trocadéro, criado em 1878. A funcionalização da arte aqui apresentada não era exatamente marcada pela inspiração ao conhecimento e à criação, supostamente dominantes no caso do Museu de Alexandria, e nem se caracterizava pelo status individual mobilizado pela coleção e o mecenato, tal qual se via na Galeria dos Escritórios.

A arte não era vista como subjetiva, mas como parte de um processo técnico de reprodução do mundo. A ciência, por sua vez, era vista como um discurso neutro, que favoreceria a racionalidade e, por conseguinte, o ordenamento político moderno. As salas do Museu do Homem deveriam ser organizadas de modo a contemplar um processo evolutivo humano que alcançasse finalmente seu ponto culminante no período histórico da Modernidade a partir de uma conjunção definida entre política e ciência. As variações observadas entre os conjuntos regionais dos objetos (Oceania, Américas, Europa etc.), eram limitadas devido aos critérios de classificação e curação, favorecendo assim a configuração de um discurso único. Como citou Grataloup (2003), o Museu do Homem dependia da manifestação de um sentido político para o discurso evolucionista. Nas palavras do autor:

Ele foi concebido segundo o paradigma evolucionista então dominante. Assim, ele integrava em um mesmo movimento a antropologia física, a prébistória e a etnologia dos "primitivos". Tal integração dos povos "sem História" supunba que eles eram percebidos como o laço, o elo que faltava entre o homem pré-histórico e o homem moderno. Este último foi excluido deste percurso museográfico: ao mesmo tempo, o Musen de Artes e Tradicões Populares foi criado sem que qualquer relação fosse estabelecida entre as duas instituições. Os criadores do Musée de l'Homme não podem ser criticados por uma visão que é considerada mais tarde redutora, eurocêntrica e unilinear: o progressismo intelectual (e politica, como a rede chamada "Museu do Homem" testemunbará logo depois sob a Ocupação) da equipe fundadora é evidente (Grataloup, 2003, p. 84).

O Museu do Homem seria configurado como uma heterotopia da ordem nos limites previstos pela definição de Foucault. Cada uma de suas salas deveria exprimir uma acumulação de tempos, uma camada do processo evolutivo, em tese irrefutável pelo cuidado na exposição das fontes e pelo cumprimento dos ritos da ciência. A ordem deveria ser sucessiva, apresentando cada uma das etapas do desenvolvimento humano, com a eliminação dos elementos subjetivos, idiossincráticos e irracionais que poderiam figurar. $\mathrm{O}$ discurso único reforçaria a mensagem de poder: não haveria retorno ao tradicional, ao natural ou ao metafísico após a ascensão do homem burguês e de sua ciência. $\mathrm{O}$ desconforto que causava no público que frequentava o museu era intencional, necessário a reafirmação do Estado e ao cumprimento de seus objetivos. Por intermédio do museu, alguns laços com o passado deveriam ser rompidos, ao mesmo tempo em que uma ordem seria imposta e comunicada. A violência institucional (racismo, imperialismo, etnocentrismo) do processo de condicionamento social era naturalizada como parte do processo civilizatório.

Porém, já no final do século XIX, os projetos museais pareceriam apresentar algumas variações em seus modelos. A arte documental, em si, se mostrava em transformação na medida em que novas técnicas de representação ganhavam visibilidade: a fotografia se popularizava e o cinema se desenvolvia neste momento. $\mathrm{O}$ esforço sistemático e violento do Estado-Nação havia esmagado as últimas chances de insurgências monárquicas na Europa, absorvido os movimentos nacionalistas que se formavam e massacrado levantes operários ou movimentos de autonomia regional. Do ponto de vista estratégico, a ampliação das tarefas e funções do Estado havia sido bemsucedida em garantir ao mesmo tempo a estabilidade territorial e a previsibilidade política. Com isso, parte do controle político da representação artística passa por um relaxamento nos primeiros anos do século XX. Os artistas ganhavam maior margem para criar projetos $\mathrm{e}$ participar de instituições públicas em sentidos distintos do modelo discutido anteriormente. Parte destes artistas passava a gozar de maior retorno financeiro, reputação e um papel mais ativo diante da política cultural do Estado. Este é o caso, por exemplo, dos arquitetos envolvidos na Reforma Haussmann, em Paris, entre outros.

Abriam-se assim janelas para o vanguardismo, no qual o apelo à subjetividade do artista se projetava no museu com uma força até então pouco conhecida. Uma situação que testou esse quadro descrito e a transformação do modelo pôde ser visto com a escultura conhecida como Homenagem à Balzac, realizada por Auguste Rodin. O projeto foi encomendado pela Société des gens de Lettres mas, após anos de trabalho obssessivo por parte de Rodin, a referida instituição contratante recusa a obra final, chocada com o resultado. O Balzac representado por Rodin não é igual a outras esculturas, com proporções neoclássicas perfeitas, mas parte de elementos mais subjetivos que derivam da percepção do escultor sobre Balzac e sobre sua obra. Um escândalo 
discutido publicamente, nas páginas dos jornais, se criou, com a defesa do caráter vanguardista da obra de Rodin conduzida pelo respeitado escritor Émile Zola. A obra acabou direcionada a um Museu específico à obra de Rodin, aberto em 1919, no qual as suas escolhas estéticas pudessem ter maior visibilidade e centralidade.

Para além do caso do affaire Rodin, notava-se no período em questão o lento rompimento que passava a arte documental e os seus efeitos sobre as coleções e exposições dos museus. Há gradual ascensão da subjetividade, na qual a "inspiração" do autor ganha maior relevância. Parte importante dos artistas defende agora a relativização do poder do mecenas ou do Estado em sua sensibilidade, assim como despreza o academicismo dominante das poderosas Escolas de Belas Artes que definiam o que era o belo ao longo do século XIX. As artes se especializam, se transformam e entram em conflito sobre os seus sentidos e visões de mundo. Muitos artistas pensavam inclusive que a função da arte pós-documental seria justamente chocar ao público, incomodá-lo em seu senso comum, problematizar suas concepções de mundo, desafiar sua percepção. Os espaços museais passavam pouco a pouco a experimentar vivas polêmicas, choques de moralidade, para além da capacidade e intencionalidade do Estado-Nação.

Iniciava-se então o desafio à heterotopia da ordem: um mesmo espaço, o museu, passava a abarcar mais do que um único sentido, ainda que a necessidade de uma plataforma para estetização colocasse a todos conjuntamente. Em paralelo às coleções antigas, de sentido documental e provedora de status social, organizam-se exposições temporárias cujos sentidos seriam conferidos mais pela subjetividade dos artistas. O desconforto causado pela heterotopia do museu seria agora oriundo também da projeção de uma individualidade em um espaço da vida pública, em um ato que, em si, transborda imoralidade e provocação. Uma série de conflitos e polêmicas passavam a cercar o museu e o seu espaço dividido na medida em que diferentes visões de mundo entravam em conflito, ainda que esta não fosse sempre a intencionalidade do artista.

De fato, o sentido do produto artístico se alterava em forma e significado, assim como o museu e o público. Um exemplo conhecido deste processo foi aquele que Marcel Duchamp apresentou em Paris, 1917, com a sua obra "Fonte". A obra se constituía na exposição de um urinol simples que ocupava o lugar de um quadro ou de uma escultura para a apreciação do público. Hoje, o valor da obra Fonte é estimado em cerca de 3 milhões de dólares. Seu interesse se encontraria justamente na provocação da substituição de um apelo ao belo por um objeto banal e vulgar ao mesmo tempo em que sugeria que a arte tivesse tanta ligação com uma estética quanto com uma especulação financeira e um status social. Para a Geografia, chama atenção também que a arte passa a ser entendida com o que se posiciona em um certo lugar de contemplação e admiração. A obra suscitou diversas polêmicas e em 2006 foi alvo de um ato de vandalismo cometido por um francês chamado Pierre Pinoncelli, que a danificou com um martelo quando estava exposta no Centro Georges Pompidou (Paris). $\mathrm{O}$ vândalo afirmou posteriormente que o ato seria uma performance artística e não uma representação, tal qual o próprio Duchamp defendia, argumentando que o artista teria apreciado o sentido do ato.

A heterotopia que se desenhava então não seria mais exatamente aquela ilustrada por Foucault. $\mathrm{O}$ ordenamento total, sintético, disposto em camadas sociotemporais que instruiriam e afetariam o público, não se definiria como a única possibilidade de uma heterotopia dos museus. A partir do século $\mathrm{XX}$, tais heterotopias seriam marcadas pelo choque de visões de mundo simultâneas, tomadas de modo competitivo e, por vezes, violento, para além de uma identidade única ou de um sentido político homogêneo. Nesse momento, talvez fosse importante lembrar que autores da geografia como Edward Relph (1991) já destacavam que os limites de heterotopias não-dependentes da ordem como um mecanismo de sua sustentação poderiam nos prover organizações espaciais mais variadas. Como afirmou o autor, a heterotopia poderia ser entendida como:

(...) um espaço no qual o desenho de centros, fronteiras e regularidades é impossivel. (...) on seja, é pluralista, caótico, projetado em detalhes, mas carece de fundamentos ou princípios universais, em constante mudança, ligados por fluxos de informação sem centro. (...) é marcado por profundas desigualdades sociais. Torna duvidosa a maioria das formas convencionais de pensar sobre paisagens e padrões (Relph, 1991, pp. 104-105).

Ao passo que os artistas ganhavam maior autonomia na organização e proposição de seus conceitos e que a arte se projetava para além dos limites das Escolas de Belas Artes e da construção da nacionalidade, os museus passavam a se tornar mais claramente espaços da autoafirmação. A possibilidade de alterar o espaço para afirmar valores, identidades e interpretações individuais ou de grupos específicos conferia maior variabilidade ao que qualificava o museu. Um exemplo disso pode ser visto na arte de Hélio Oiticica. Anarquista, 
o artista plástico sugeria limites para a sua concepção artística que se chocavam com as políticas culturais brasileiras. Em primeiro lugar, debates sobre problemas sociais poderiam vir ligados a elementos da etnia, da sexualidade, do corpo, da identidade e/ou da religião. Segundo, suas obras traziam uma quebra no entendimento do objeto artístico como um todo, o que poderia ser visto nas suas instalações (salas, quartos), nas caixas, roupas ou danças que sugeria como produto. Terceiro, a arte era entendida como um jogo performático e não como um objeto de contemplação, distante de todos. Em quarto lugar, o público era convidado a interagir com o objeto artístico, tocá-lo, alterar sua posição, entrar na instalação (se colocar no lado de dentro). Por último, não haveria sentido único ao produto, cabendo àee arte o entendimento de uma relação entre sujeitos e objetos. Como consequência, Oiticica foi expulso do Museu de Artes Modernas do Rio de Janeiro em 1965. Suas exposições temporárias não coincidiam mais com os limites mais tradicionais da arte e procurava reverberar elementos de uma concepção vanguardista que ganhava maior visibilidade na segunda metade do século XX. Os seus parangolés, cosmococas ou bólides eram parte de micropolíticas que queriam alterar os alcances do museu, ainda que os impactos entre o público geral fossem comedidos diante do desinteresse ou desconhecimentos sobre os ritos e capacidades das artes.

Outros casos poderiam ser evocados como parte de um panorama para a discussão da heterotopia dos museus brasileiros no início do século XXI. Não temos a pretensão de exaurir aqui todas as possibilidades de organização e entendimento do campo museal. No entanto, os momentos enfocados anteriormente nos possibilitam entender a variabilidade nos arranjos entre arte e política, assim como suas projeções espaciais. A transformação de um quadro de heterotopia $\mathrm{da}$ ordem para uma heterotopia caótica, desordenada, parece ser o pano de fundo para o processo de redefinição dos espaços museais e de suas possiblidades no Brasil.

\section{As territorialidades da guerra cultural nos museus brasileiros}

A heterotopia dos museus brasileiros, criticados, vandalizados, queimados, sucateados, parece exigir que os coloquemos como espaços de guerras culturais. Isso significa que, para além da carência dos recursos, da crítica da finalidade pública da exposição ou das polêmicas comunicativas movidas a partir dos limites do entendimento do belo e do subjetivo em geral, aquilo que parece ganhar visibilidade no museu é um momento específico no qual a política e suas energias são direcionadas a outras localidades, com consequências que ainda estão sendo compreendidas neste momento. A ideia geral é que a ação no e pelo território seria reveladora de uma moralidade e/ou justiça que, na concepção de certos agentes, precisam ser reconhecidas como matéria de discussão pública. De modo adicional, quebraria-se a inércia e a estabilidade de certos códigos jurídicos consolidados que protegeriam e tornariam mais lentas as mudanças no sistema político. O museu, de um momento a outro, passa a ser colocado como palco no qual direitos, leis e discursos são proferidos, debatidos e desafiados, reunindo territorialidades que almejam influenciar não apenas a organização de seu espaço, mas um efeito duradouro sobre a sociedade.

Robert Sack (1986) definiu territorialidade como uma série de posturas projetadas por e pelo território, cujo principal objetivo é influenciar o comportamento de outros e codificar as suas posturas a partir de um jogo de visibilidade. Em suas palavras:

Territorialidade envolve uma forma de classificação
que é extremamente eficiente sob certas
circunstâncias. A territorialidade classifica, pelo
menos em parte, por área e não por tipo (...). A
territorialidade pode ser fácil de se comunicar porque
requer apenas um tipo de marcador ou sinal - a
fronteira. A fronteira territorial pode ser a única
forma simbólica que combina direção no espaço e
uma declaração sobre posse ou exclusão. A
territorialidade pode ser a estratégia mais eficiente
para impor o controle, se a distribuição no espaço e
no tempo dos recursos ou coisas a serem controladas
se situarem entre onipresença e imprevisibilidade.
(...) A territorialidade fornece um meio de reificar o
poder. Poder e influência nem sempre são tão
tangiveis quanto os rios e montanhas (...). A
territorialidade torna os potenciais explícitos e reais,
tornando-os "visiveis". (...) A territorialidade pode
ser usada para desviar a atenção da relação entre
controlador e controlado para o território. (...) Ao
classificar pelo menos em parte por área, e não por
tipo, a territorialidade ajuda a tornar impessoais os
relacionamentos (Sack, 1986, pp. 32-33).

Dois casos chamaram atenção nos últimos 5 anos pelo fato de não apenas manifestar dilemas sobre o financiamento ou discussões sobre o sentido da arte e das ciências em um espaço cultural público, mas por indicar um papel destas mesmas ao centro da atividade política brasileira por intermédio de territorialidades. O primeiro se 
refere à polêmica da exposição conhecida como 'Queermuseu - cartografias da diferença na arte brasileira' e o segundo caso se refere à performance 'La Bête'. O 'Queermuseu' foi uma exposição temporária que contava com 270 obras e que estava prevista para ser apresentada no espaço Santander Cultural, em Porto Alegre, entre Agosto e Outubro de 2017. Os diversos arranjos vanguardistas e provocativos entre sexualidade, religiosidade e identidade em seus quadros e esculturas teve como respostas campanhas, manifestações e denúncias ao longo de sua duração. Ao longo de sua curta temporada em Porto Alegre, com a exposição tendo sido suspensa pelo museu em Setembro de 2017, e do esforço da sua reedição na cidade do Rio de Janeiro no ano seguinte, foi possível entender os espaços museais como matérias de vivo sentido político, para além da política cultural. Agir sobre esses espaços exigiria a composição de uma territorialidade, manifesta tanto física quanto imaterialmente, tendo como objetivo mobilizar um efeito de uma guerra cultural sobre o sistema político como um todo.

A polêmica foi iniciada dias após a inauguração da exposição, com ação de grupos como o Movimento Brasil Livre (MBL), artífice do liberalismo econômico e do conservadorismo social, em soma a associações cristãs, de youtubers como Felipe Diehl e Rafinha BK e a participação de alguns deputados, como Marcel Van Hattem e Magno Malta, que difundiram primeiramente uma campanha difamatória em redes sociais (facebook, youtube etc.), na qual acusavam a totalidade da exposição como herética e apologética à zoofilia, pedofilia e imoralidades em geral. Tal campanha difamatória cumpria tarefa de classificação simbólica do território, tal qual havia estabelecido a formulação de Sack (1986). Não se mostrava, então, um detalhamento das acusações ou de uma abertura de canal de comunicação com a mostra ou seus curadores para ajustes da política de acesso à exposição: o clamor pela proibição e pela punição dos seus envolvidos ganhava sentidos de inibição do caráter público da exposição. De acordo com Renan Santos (como citado em Amorim \& Tavares, 2017), um dos membros do MBL, o conhecimento mais detalhado da exposição era desnecessário, frente ao caráter de imoralidade que supostamente a animaria: "Eu não preciso ir à exposição, poderia estar na Groenlândia e ser contra o pressuposto do uso de dinbeiro público numa exposição que vilipendia imagens religiosas".

O museu ganhava visibilidade até então desconhecida, sem poder recorrer aos códigos de política pré-estabelecidos para balizar questões de conflito. O Banco Santander, financiador do espaço Santander Cultural, foi, em seguida, pressionado por estes mesmos agentes, por intermédio de críticas públicas, ameaças de boicote e de fechamento de contas. De acordo com Amorim e Tavares (2017), ao menos três diretores do Banco foram ameaçados de morte. A exposição acabou suspensa e o dinheiro público viabilizado via Lei Rouanet foi devolvido pelo Santander - em nota ii, o Banco argumentou que "Ouvimos as manifestações e entendemos que algumas das obras (...) desrespeitam símbolos, crenças e pessoas, o que não está em linha com a nossa visão de mundo. Quando a arte não é capaz. de gerar inclusão e reflexão positiva, perde seu propósito maior, que é elevar a condição humana" (como citado em Mendonça, 2017). Influenciadores digitais passaram a fazer manifestações as portas ou mesmo dentro da exposição, no qual hostilizavam o público que por ali passava, ao perguntar se são pedófilos ou tarados (Amorim \& Tavares, 2017), enquanto faziam filmagens e avaliações dos crimes e pecados que poderiam ser encontrados nas obras de arte a sua volta. Denúncias foram direcionadas ao Ministério Público e o curador da exposição, Gaudêncio Fidelis, foi levado por condução coercitiva a se apresentar ao Senado Federal para apresentar depoimento na Comissão Parlamentar de Inquérito sobre Maus-Tratos Infantis. Em paralelo, o referido curador manifestava que estava sendo perseguido e ameaçado e que caberia ao museu garantir a segurança contra a projeção territorial de forças conservadoras: "Havia a alternativa de aumentar a segurança e manter a exposição aberta. Eu passei a receber ameaças - e recebi mais de 100 - justamente depois que ela foi encerrada" (Fidelis como citado em Amorim \& Tavares, 2017). O controle de acesso tomava sentido mais claramente territorial, ao promover abertamente as condições para dizer o que poderia ser exposto ou não no espaço museal para além dos marcos regulatórios. A velocidade das trocas de políticas por parte dos organizadores e políticos a partir das territorialidades exercidas por pequenos grupos motivou que outras ações tomassem lugar.

$\mathrm{O}$ 'Queermuseu' foi reeditado no ano seguinte no Rio de Janeiro, por meio de uma bemsucedida campanha de financiamento coletivo, sem uso de recursos públicos, e foi exposta em espaço da Escola de Artes Visuais do Parque Lage. A visibilidade que o boicote promoveu foi decisiva para conferir popularidade à mostra, assim como aos grupos que mobilizavam politicamente os seus conteúdos. Grupos heterogêneos relativos à política, à arte, à educação e aos direitos de minorias organizaram eventos em paralelo à exposição. Os deputados Jean Willys e David Miranda fizeram palestras, assim como o curador da exposição Gaudênio Fidelis e o artista Wagner Schwartz, espaços de fala foram abertos à diversas 
associações LGBTQI+, além de performances teatrais realizadas como incremento à proposta não-interativa da exposição. Apesar do protestos e ameaças, a mostra passou um mês em exposição no referido espaço carioca, tendo reunido um público de quase 40 mil pessoas ao longo do período (Barros, 2018). A maior parte do público parecia ser movida pela curiosidade criada pela polêmica e não por um interesse específico nas formas artísticas expostas, como revela as dezenas de entrevistas realizadas com o público. Em registro da jornalista Luiza Barros, Roberto Cortes, aposentado, um dos vários entrevistados, revela um pouco deste quadro: "Queria ver se tinha algo de estranho. Não vi, só acho que estou muito por fora da arte descartadas antes da sua formalização nas diversas instâncias jurídicas, mas o efeito político dos depoimentos parece ter sido claro, tanto pelo crescimento das manifestações favoráveis e contrárias à exposição nos meios de comunicação, quanto no fechamento ou nas manifestações dentro ou em volta da exposição. Diversos prefeitos (Rio de Janeiro, São Paulo, Porto Alegre), líderes religiosos e grupos sociais mobilizaram os conteúdos da exposição, sem expectativa de diálogo ou proposta de resolução que não passasse pela afirmação do seu descontentamento ou desinteresse. O então deputado federal Jair Bolsonaro chegou a afirmar que era "necessário fuzilar os autores dessa exposição" em entrevista (TV

Figura 1 - Fila do 'Queermuseu’ na EAV Parque Lage, Rio de Janeiro, 2018

A inauguração da exposição 'Queermuseu’ no Parque Lage revelava a construção de uma territorialidade reativa, no qual diversos grupos se mobilizavam em defesa da arte e da mobilização política vanguardista derivativa desta, para além do interesse dos indivíduos na composição estética. Forte aparato de segurança é disponibilizado para viabilizar o livre acesso. Longas filas se formaram na entrada, em uma concentração incomum ao público médio da Escola de Artes Visuais do Parque Lage. O museu é fortemente mobilizado em prol de forças políticas opostas em seus fundamentos e valores daquilo que era visto na mesma mostra quando da sua exposição no Espaço

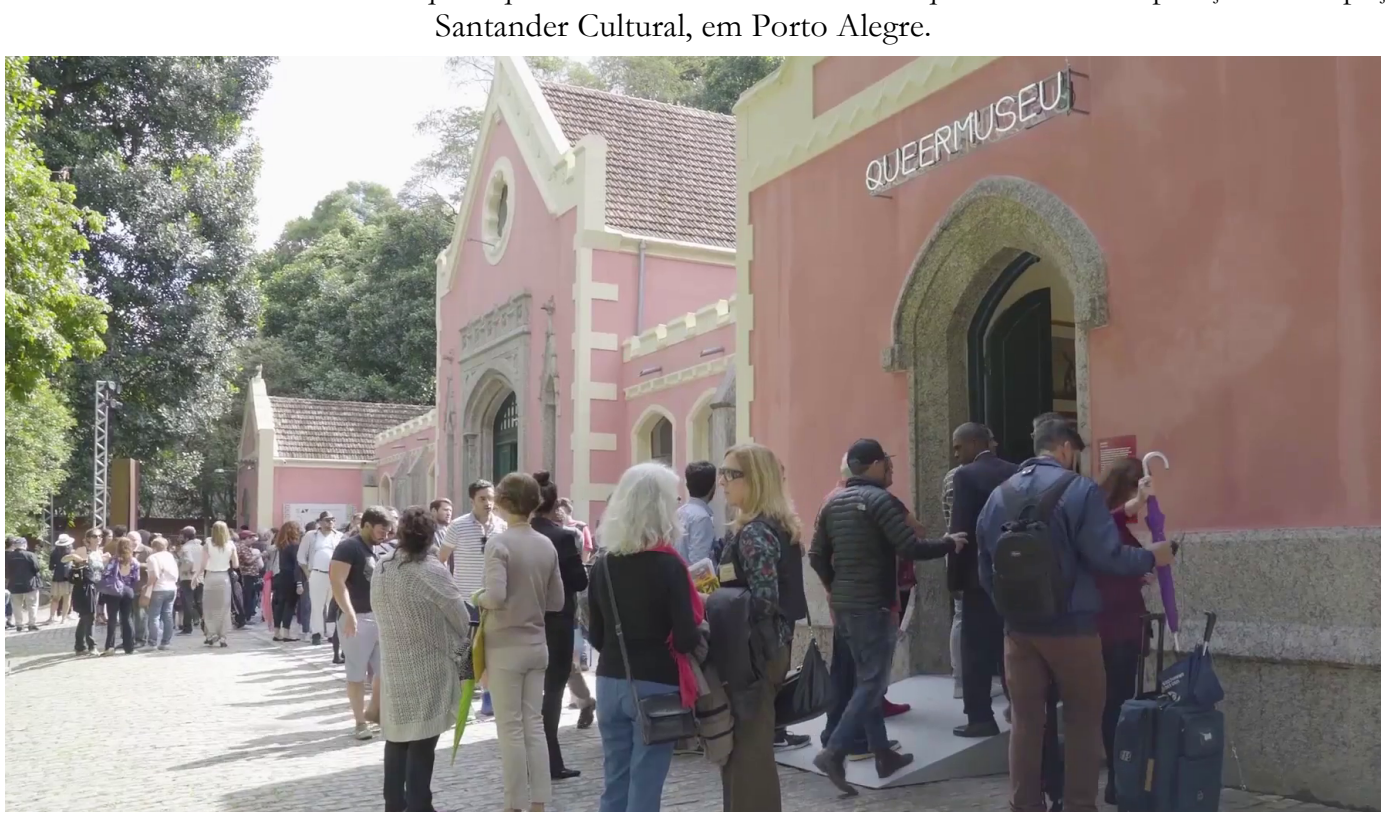

Fonte: EAV Parque Lage. Recuperado de: https://vimeo.com/302120907. Licença Creative Commons.

atual. Para mim, não se debe censurar. Só sou a favor de ter um limite de idade" (Cortes como citado em Barros, 2018). A força reativa que anima a territorialidade seria organizada de modo multipolar, com efeitos concretos para a consolidação da exposição e para o Parque Lage, uma vez que os recursos acumulados no crowdfunding serviram à reforma de partes do Parque.

Ao longo de toda a duração de sua proposição, seu curador e seus artistas foram chamados a depor em diferentes instâncias da justiça e do poder legislativo, sem que fossem diretamente implicados em processos públicos. Todas as denúncias foram
Verdade, 2017) e mobilizou a polêmica em diferentes momentos de sua campanha presidencial como exemplo da banalidade das políticas culturais no Brasil e da necessidade de uma moralização dos gastos públicos com cultura por intermédio de reformas na Lei Rouanet e de uma redução ou extinção do Ministério da Cultura como um todo. Nessas oportunidades, os espaços museais eram abordados pelas polêmicas de poucas obras para viabilizar poderes políticos maiores, aqueles de reformar instâncias gerais da sociedade. Talvez, ao longo da polêmica, o curador da exposição 'Queermuseu' tenha ganhado individualmente 
importância no cenário artístico pela posição pública que foi levado a assumir; no entanto, do ponto de vista da política cultural, o efeito é que seus espaços tenham passado por um processo de rupturas de sua legitimação pública, fechamentos, redução de funcionamento, suspensão de exposições, quebras de reputação. Tudo isso partiu em primeiro plano de um limite de imposição da força conservadora, dissociada da lógica da arte ou do campo da cultura como um todo, para alcançar os efeitos concretos em uma instituição que é política.

$\mathrm{Na}$ performance 'La Bête', realizada pelo coreógrafo Wagner Schwartz durante anos (desde 2015) no Museu de Arte Moderna de São Paulo, o

artista se movimenta com uma réplica de uma escultura de Lygia Clark (Os Bichos). Não há nesta obra um objeto artístico similar ao consumo de um quadro ou uma escultura, através de uma representação. Trata-se de uma performance no qual é o corpo do artista que cumpre o papel de provocação do público em questão. Esse corpo nú, visível e exposto ao público, pode ser tocado, movido e manuseado por parte do público ao longo do ato performático. A possibilidade desta interação intenta um rompimento da barreira com o público, assim como o desnudamento dos valores e ideias de quem ali se encontra presente. Tal desconstrução do indivíduo, figurado no espaço cênico tanto por intermédio do público quanto pelo artista/obra de arte, cumpre elementos de uma sugestão heterotópica. A arte sugerida não é mais trazida pelo contorno do objeto, e sim pela experiência e pela interação. $\mathrm{O}$ museu não é mais uma coleção de pedestais e de molduras, mas cumpre o papel de um receptáculo ou caixa no qual a desconstrução toma lugar. Nesse processo, as críticas de diversos sentidos das instituições de uma sociedade ganharam visibilidade. De acordo com Schwartz:

Para que La Bête aconteça, é importante que aqueles que estão na galeria on no musen estejam dispostos a repensar o lugar do espectador. Lugar esse que, paradoxalmente, é impraticável nesta performance. Algumas pessoas entram em cena para manipular as "dobradiças" do Bicho humanizado. Outras ficam do lado de fora e, do mesmo modo, atuam sobre as ações que vão acontecendo, quando as comentam entre si. Uma pessoa pode também abandonar a performance. Ninguém é obrigado a aguardar o seu término. E, como La Bête é feito pelo público, as pessoas podem ainda propor um fim à ação. La Bête evidencia a cultura do outro, o seu jeito de narrar. Depois de sua apresentação no $M A M$, no Parque do Ibirapuera, em São Paulo, a performance continuou a ser articulada e a se desdobrar, mas de uma maneira diferente daquela que Lygia Clark e en propomos. La Bête foi para fora de todos os espaços artísticos e continuou, nessas outras articulaçoes, a mostrar a cultura das pessoas que dobram, desdobram e redobram uma performance que, nesse caso, sequer foi assistida (Schwartz como citado em Brum, 2018).

O jogo da interação e da desconstrução promovido em 'La Bête' foi acusado de apologia à pedofilia ao permitir a presença e interação de crianças com o corpo desnudo do artista (a referida criança tocou o pé de Schwartz). Tal interação foi circunstancial, ou seja, não era o modo de desenvolvimento de toda a performance, mas um caso estabelecido em um dos dias de apresentação, com a presença da mãe da criança, diante de um público considerável e após todos terem sido previamente informados sobre o seu teor. Apesar da performance não incluir qualquer erotização em sua dinâmica, a nudez foi interpretada por segmentos da população como reflexo de um ato sexual. A partir de denúncia promovida pelo MBL, o Ministério Público abriu investigação contra o artista. O referido movimento estabeleceu uma campanha difamatória nas redes sociais, que derivaram em petições e abaixo-assinados pelo cancelamento da exposição, pequenas manifestações a porta do MAM-SP, assim como mensagens direcionadas aos poderes públicos. $\mathrm{O}$ espaço museal tem ganhado nos últimos anos diversas polêmicas e manifestações acerca da moralidade e da sexualidade. A liberdade na composição vanguardista, que se promoveu ao longo das últimas décadas no espaço museal, tem sido criticada na medida em que poderia ferir a religiosidade ou a estrutura familiar.

A existência de manifestações, sejam estas nas redes sociais ou dentro do próprio museu, são partes da vida pública. Não existe, de fato, um espaço que seja completamente dissociado do desenvolvimento da política e a própria presença de recursos públicos e da publicidade da arte são suficientes para mobilizar o espaço museal em uma série de polêmicas. Porém, os museus não são regidos pelos mesmos ritos, discursos e sentidos que uma Câmara dos Deputados ou um forum de debates. Não há, por exemplo, estruturas ou arranjos dos seus espaços para o contínuo debate de interpretações, ou regras melhor definidas sobre os limites das mobilizações e das ações em seus espaços. Se, no Congresso Nacional, há tempo de fala dedicado às bancadas, normas de decoro sobre os seus conteúdos e um texto que rege o alcance máximo das provocações a partir da constituição, assim como detalhamentos bastante específicos 
para os processos de mudança, nada disso tem lugar no espaço museal e de suas polêmicas. Para o bem e para o mal, a constituição apresenta lentidão em seus processos de mudança, enquanto a força que rege um espaço como do museu é escorado no princípio do julgamento, tal qual Kant (2012) havia previsto, nos quais os sentimentos e a memória são os elementos dominantes. A projeção de indivíduos e de seus valores em um mesmo espaço museal teria sido, inicialmente, pensada no limite das percepções e não como um jogo pelo qual as relações de poder se configurem naquele momento e naquele lugar.

Em um contexto político no qual as instituições formais do poder são questionadas em sua legitimidade pela corrupção, lentidão em suas reformas e dissociação da vida cotidiana, parte da aproximação que se realiza em relação ao público institucional (ainda que sejam direcionados a interferir nestes!), mas são os valores, as identidades, as visões de mundo, a etnicidade, a sexualidade ou a religiosidade que normalmente ganham lugar (Valverde, 2019). O museu é alçado a uma posição para o qual não foi anteriormente pensado: um espaço central para o desenvolvimento das polêmicas políticas, ao invés de um espaço secundário, de reforço aos mecanismos de coesão social. Não a toa, políticos passam a se manifestar sobre museus em suas campanhas, como ocorreu com João Doria e Marcelo Crivella, que se tornaram prefeitos de São Paulo e do Rio de Janeiro, respectivamente, no ano de 2016. Ambos argumentaram em suas campanhas que iriam proibir a exposição 'Queermuseu' em suas cidades como parte de um compromisso público. Tais promessas possuiriam

Figura 2 - Manifestação contrária à performance 'La Bête’ no Museu de Arte Moderna de São Paulo, 2017

Grupos conservadores se mobilizam em piquetes e passeatas em reposta à campanha difamatória promovida nas redes sociais contra o artista Wagner Schwartz e o Museu de Arte Moderna de São Paulo. A territorialidade retoma o nacionalismo e o cristianismo exacerbados como símbolos, o bloqueio e o boicote como estratégias e o repúdio à cultura como efeito. O Museu de Arte Moderna de São Paulo manteve a exposição e defendeu a subjetividade do artista, mas sofreu com a judicialização do conflito.

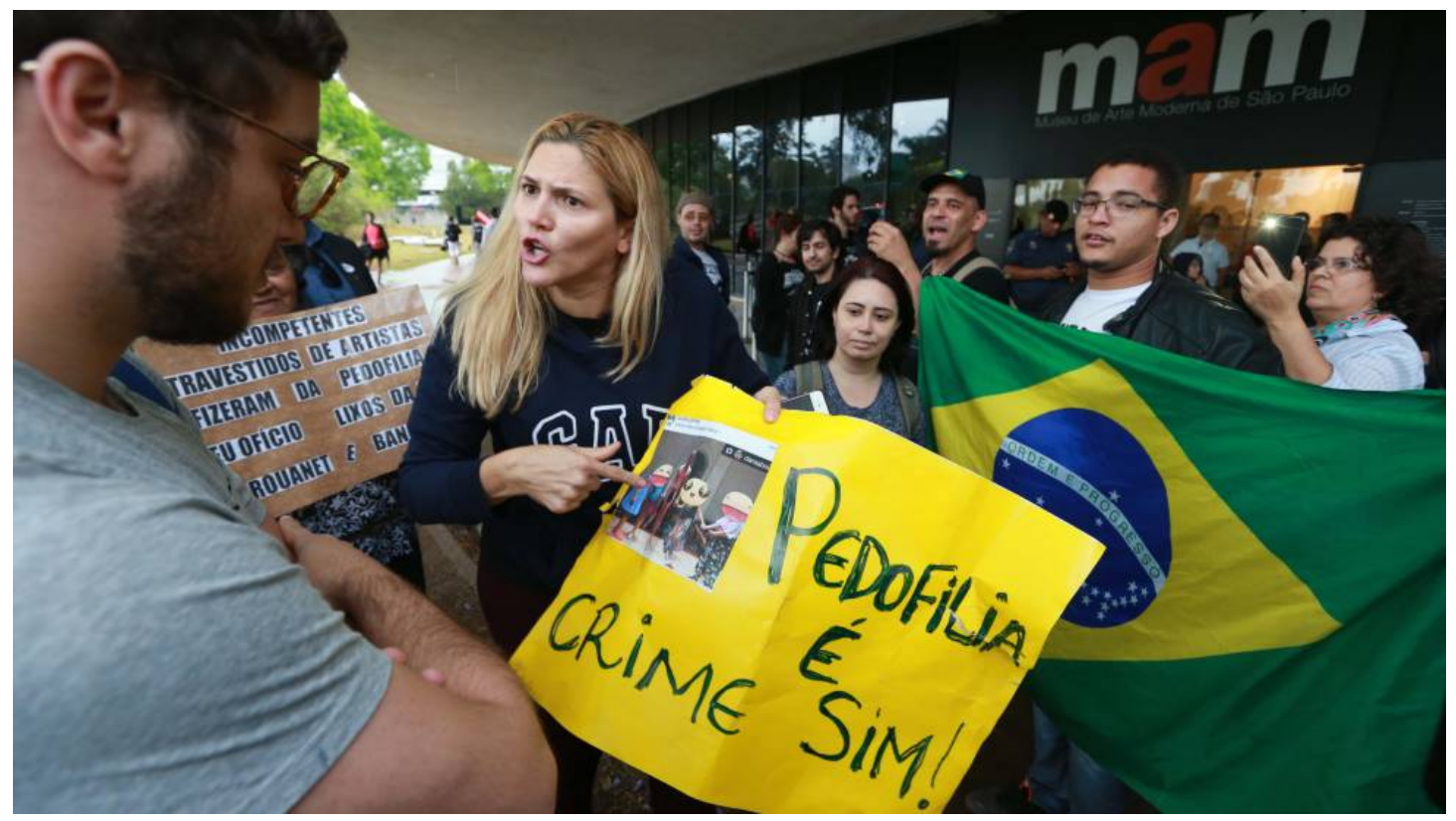

Fonte: Foto de Tiago Queiroz (Estadão/Conteúdo). Recuperado de:

https://cultura.estadao.com.br/fotos/artes,protesto-no-mam-termina-em-agressao-fisica, 800110 . Attribution: NonCommercial-ShareAlike 2.0 Generic (CC BY-NC-SA 2.0).

parece depender de intervenções que se construam em outros lugares. Há um deslocamento da política e das suas energias para todo um novo conjunto de agentes e processos. Chamamos esse processo de guerra cultural, na medida em que a matéria do que anima esse debate não é a luta de classes, não é o modelo econômico ou o sentido da política uma dupla polêmica: (1) sobre a intervenção de uma instância da política sobre a autonomia e vanguarda artísticas ao legislar sobre o que pode e o que não pode ser feito; (2) ao tentar definir ações de museus que não fariam parte do patrimônio cultural municipal. 
Ambos os casos enfocados destacam os vícios da política de museus e das instituições culturais em geral: são todas vistas como excludentes, elitistas, dispendiosas e imorais. O discurso que critica os museus normalmente parte do ponto de que não haveria sustentabilidade às suas exposições e coleções, uma vez que o custo de manutenção seria caro (mesmo o Museu do Louvre não é capaz de se manter apenas com os recursos tirados das suas bilheterias), parte importante do público se mostraria agredida pelas suas mostras e coleções (seja pelo racismo institucional, seja pelos desrespeitos aos dogmas religiosos ou à normatividade sexual) e suas conexões com o mundo atual são severamente questionadas. Exigese uma aproximação, ainda que os agentes que promovam estas demandas não estejam de acordo em qual direção. Alguns sugerem uma repolitização dos museus como parte de uma absorção das demandas de políticas identitárias relativas a grupos minoritários, excluídos e marginalizados dentro de nossa sociedade. Seus símbolos deveriam ser colocados à frente da política de museus, a razão de ser da organização dos seus espaços como forma de denúncia e sensibilização da sociedade como um todo. Outros clamam pela despolitização quase total do museu, com a qual os símbolos da cultura nacional possam ser novamente estabelecidos como registro dominante $\mathrm{e}$ arte possa ser funcionalizada mais uma vez. Argumenta-se que os custos da manutenção museal (segurança, estrutura, controles de risco, seguros, manuntenção, pagamento de artistas, produção artística) devem ser transferidos para agentes privados que, de acordo com os seus defensores, conseguiriam buscar a sustentabilidade econômica. Ambos demandam novos canais de projeção através da mídia digital e novas tecnologias, sentido didático ao museu e temas vivos e socialmente compartilhados.

Problematizados pela crise econômica e pela polarização política, os espaços museais se veem como palco de intervenções, muitas vezes de ordem negativa. A heterotopia dos museus é causada pelo desconforto que o discurso sobre a necessidade das desconstruções promove. A arte e a ciência não poderiam seguir suas vanguardas, mas apenas ecoar ou refletir as demandas de grupos específicos da sociedade, portadores de novos elementos da moral. A inexistência de consensos acerca das formas de reorganização ao mesmo tempo em que se nota que os recursos disponíveis são escassos coloca os museus como pauta secundária e negativa. Tais grupos possuem diferentes recursos financeiros e capacidades de intervenção na sociedade, mas enxergam nos museus mais problemas do que oportunidades.
Dentro destes limites de entendimento, a melhor possibilidade é que, de fato, os espaços museais consigam repetir algo que já tenha sido produzido em outra instância da sociedade. O exercício de suas territorialidades colocaria desafios à normalidade que podem consumir tais instituições em seus sentidos modernos. Nesse processo, cultura e ciência parecem pulverizados e seus espaços seriam portadores da imoralidade. As crises da modernidade seriam vivenciadas como parte de um sistema de deslocamentos de seus recursos e instituições, conduzidos ainda sem um sentido claro para a reorganização. Estaremos às vésperas de um novo ciclo de coleções privadas, interativas a partir de uma seleção de público e de seus espaços, em um sistema de aberturas e fechamentos (Foucault, 2001) que permitiriam que as necessidades grupais pudessem ser simplificadas e qualificadas para além da estratégia nacional? Em caso positivo, a desconstrução da heterotopia da ordem dos museus seria sucedida por esforço de uma consolidação de nova heterotopia da ordem, agora capaz de lidar com as tecnologias e os agentes de um mundo mais diverso e, paradoxalmente, menos tolerante.

\section{Conclusão}

Ao longo dos últimos 10 anos, o limitado orçamento dedicado à cultura no Brasil tem apresentado notável tendência de queda: enquanto concentrava cerca de $0,71 \%$ em 2010 , o orçamento diminuiu para cerca de $0,57 \%$ em 2014 e a previsão é que gire em torno de 0,39\% em 2019 (Martí, 2016). Tais valores se referem à Lei Orçamentária Anual, mas tem efeitos sobre o sistema cultural como um todo, uma vez que a renúncia fiscal possibilitada pela Lei Rouanet é parte decisiva da sustentação dos museus privados. Ainda que uma questão conjuntural, relativa à crise econômica, tenha clara expressão, trata-se de uma questão mais profunda, no qual o museu não cumpre a mesma força discursiva dos meios de comunicação e mídias digitais frente ao projeto do Estado, o que diminui a sua relevância na constuição de uma força de coesão social. Em paralelo a este desafio, observa-se a preocupação com a frequência dos visitantes que parece ainda depender diretamente das políticas educacionais - frente às reformas do ensino fundamental e médio, os museus temem ver parte do seu retorno minguar. Diversos julgamentos são realizados por vários canais: o museu é visto como banal, imoral, imperialista, herético, perdulário, burguês, desinteressante, racista, insensível e, de modo geral, dissociado do público. Exige-se o espelho (no qual o museu 
exprima com precisão o que é o mundo, o que há de excepcional nele) em detrimento da vanguarda, o que poderia significar uma alteração significativa do papel da cultura, da arte e do museu. Qual necessidade deve ser movida em seus espaços?

Frente aos ataques e manifestações que tornam museus espaços de viva polêmica política em um cenário de dúvidas e incertezas, artistas e curadores se mobilizam em um movimento paradoxal: o número de exposições, salas, financiamentos e eventos diminui, enquanto o número de ingressos vendidos para consumo cultural em museus aumenta. A visibilidade ganha pelo espaço museal frente às polêmicas do deslocamento de parte importante das energias da política possui efeitos variados. Primeiro, um conjunto de pequenas e médias salas, sobretudo localizadas em cidades médias e no interior, fecha suas portas pela dificuldade em estabelecer a manutenção de suas obras ou viabilizar os contratos com os artistasiii. O cancelamento dos editais vinculados ao Ministério da Cultura e as contenções de outras políticas culturais em diversas escalas (federal, estadual e municipal) impedem que uma parte dos custos de manutenção e segurança seja sustentado. Trata-se de uma tendência consolidada no Brasil há cerca de 20 anos e agravada nos últimos 5 anos. De fato, a concentração dos equipamentos culturais no Brasil é superior inclusive àquela observada na indústria. Como resultado direto da crise econômica e da crise política, tais instituições mais vulneráveis e menos tradicionais encontram mais dificuldades em se sustentar, estabelecendo uma diferenciação ainda mais clara entre o público que tem acesso e aquele excluído da atividade museal. Um exemplo é o risco eminente de fechamento do Museu Afro Brasil, que manifesta publicamente o processo de redução de pessoal, que realizava a manutenção e apresentava a coleção ao público, formado sobretudo por alunos da escola pública.

Em segundo lugar, os museus mais tradicionais, com mais recursos, alguns ligados às universidades e localizados nas capitais das unidades federativas, realizam campanhas de atração mais agressivas para garantir o público frente as ameaças da contemporaneidade. Para torná-las mais efetivas, a retórica da perda é mobilizada, em um discurso que destaca o risco de que o desmantelamento das políticas culturais atinja instituições como os Museus de Arte Moderna do Rio de Janeiro e São Paulo. O público é engajado pelo apelo à instituição ou à cultura em geral, e não pela arte ou pelo artista de modo direto. A seleção do que é exposto ganha sentido mais tradicional, trazendo público e bilheteria a partir do interesse em mostras de artistas consolidados ou famosos, como é o caso da recente exposição dedicada à obra de Tarsila do Amaral ou à mostra da arte do cineasta Tim Burton. O tempo de exposição é aumentado, evitando os custos das alternâncias das exposições temporárias (Martí, 2016). As obras atuais, as exposições vanguardistas, o caráter polêmico ou provocativo fica em segundo plano para garantir a sobrevivência da instituição. $\mathrm{O}$ convite à interação é realizado em um plano reduzido, por intermédio das selfies ou de alguma oficina que mobilize a memória e a identificação daqueles que passaram pela exposição. Não se trata, aqui, de interagir diretamente com os quadros ou esculturas, muito menos de reagir de modo mais direto e político, mas retornar à contemplação e à admiração. De acordo com esta visão, o museu precisaria ser espaço de maior previsibilidade para sobreviver. Seria preciso transcender o retorno econômico da bilheteria pelo interesse na exposição, e ganhá-lo na locação dos espaços museais, na venda das loja de souvenirs ou na cafeteria, em eventos excepcionais (shows, palestras etc.).

De um modo geral, a leitura que se estabelece é que o museu passa a ser visto como uma heterotopia distópica, na qual sua vivência é estabelecida com ultraje, com enfado e com desconforto frente aos desenhos que o animaram recentemente. Para sobreviver, em parte, parece se exigir dos seus espaços a capacidade de transformação, de desconstrução, de manifestar o descontentamento. Seu público entra e sai do mesmo modo, com pouca capacidade de sensibilização frente ao exposto. $\mathrm{Na}$ melhor das hipóteses, tal sentido de nova heterotopia para os museus cumpre o papel do espelho, no qual a vanguarda artística, a subjetividade e a figura do autor perdem um pouco do seu dinamismo. Aquilo que de fato é procurado poderia ser entendido por uma interação com o público para além do sentido direto da arte, vinculado às identidades que se estabelecem e se fortalecem fora dos limites do museu.

Tal necessidade de afirmação consome importante parte de seus recursos em um contexto de crise econômica e da representatividade política, que desafiam o museu a não inspirar reações mais fortes, sob o risco de que seus espaços sejam alvo de censuras, boicotes, cortes de gastos e manifestações que inviabilizariam o seu funcionamento. As territorialidades exercidas nesta guerra cultural comprometem as próprias funções e sentidos que qualificam a existência dos museus nos dias de hoje. Parece pressioná-los em direção às políticas identitárias, as lógicas do consumo e para a intermediação privada a partir das mídias digitais e instrumentos tecnológicos. A medida 
provisória que sugeriu a extinção do IBRAM (MP $\mathrm{n}^{\circ} 850 / 2018$ ) e a criação de uma fundação privada para captação de recursos em 2019 é ilustrativa deste processo. Será o espaço do museu capaz de renovar a sua capacidade de inspiração?

\section{Referências Bibliográficas}

Amorim, D. \& Tavares, F. (2017). Como movimentos ultraconservadores conseguiram encerrar a exposição Queermuseu. Revista Época. Recuperado de: https://epoca.globo.com/brasil/noticia/201 7/09/como-movimentosultraconservadores-conseguiram-encerrarexposicao-queermuseu.html.

Barros, L. (2018). 'Queermuseu': público lota o Parque Lage no último dia de exposição. Recuperado https://oglobo.globo.com/cultura/artesvisuais/queermuseu-publico-lota-parquelage-no-ultimo-dia-de-exposicao-23074486.

Brum, E. (2018). Fui morto na internet como se fosse um zumbi da série The Walking Dead. Jornal El País. Recuperado de: https://brasil.elpais.com/brasil/2018/02/12 Lopinion/1518444964_080093.html.

Foucault, M. (2001). Des espaces autres. Dits $e$ Écrits, tome 2: 1976-1988. Paris: Gallimard, 1571-1581. Recuperado de: https://www.cairn.info/revue-empan-20042-page-12.htm

Geoghegan, H. (2010). Museum geography. Geography Compass 4 (10), 1462-1476.

Grataloup, C. (2003). Les périodes de l'espace. Espaces Temps 82, 80-86.

Harvey, D. (2008). A condição pós-moderna. São Paulo: Loyola.

Instituto Brasileiro de Museus - IBRAM. (2019). Os musens. Recuperado de: http://www.museus.gov.br/os-museus/

Kant, I. (2012). Crítica da Faculdade do Juíro. Porto Alegre: Forense Universitária.

Martí, S. (2016). Crise força museus a cortar mostras e aumentar duração de exposições. Recuperado de: https://www1.folha.uol.com.br/ilustrada/2 016/03/1752593-crise-forca-museus-acortar-mostras-e-aumentar-duracao-deexposicoes.shtml

Matos, T. (2019). Museus em alta: $1^{\circ}$ semestre de 2019 tem recordes de público pelo Brasil. Recuperado de: https://g1.globo.com/poparte/noticia/2019/08/12/museus-em-alta1o-semestre-de-2019-tem-recordes-depublico-pelo-brasil.ghtml.
Mendonça, H. (2017). Queermuseu: O dia em que a intolerância pegou uma exposição para Cristo. Recuperado de: https://brasil.elpais.com/brasil/2017/09/11 /politica/1505164425_555164.html.

Mitchell, D. (2000). Cultural Geography - A critical introduction. Oxford/Maldern: Blackwell.

Relph, E. (1991). "Post-modern geography". The Canadian Geographer, 35 (1), 98-105.

Sack, R. D. (1986). Human Territoriality - its theory and history. Cambridge: Cambridge University Press.

Soja, E. (1995). Heterotopologies: a remembrance of other spaces in the citadel of L.A. In: WATSON, S. e GIBSON, K. (ed.). Postmodern cities and spaces. Oxford: Blackwell, 14-34.

Soja, E. (1993). Geografias Pós-Modernas. Rio de Janeiro: Jorge Zahar.

TV Verdade. (2017). Bolsonaro diz que "tem que fuzilar" quem fez a exposição Queermuseu. Canal de divulgação do Programa de Debates. Recuperado de: https://www.youtube.com/watch?v=871pZ zgG38g.

Valverde, R.R.H.F. (2019). Guerra cultural e multiterritorialidade. Carlos, A.F; Cruz, R.C.A. A necessidade da Geografia. São Paulo: Contexto, 215-226.

Valverde, R.R.H.F. (2009). Sobre espaço público e heterotopia. Geosul, 24, 7-26. Recuperado de: https://periodicos.ufsc.br/index.php/geosu 1/article/view/2177-5230.2009v24n48p7

Valverde, R.R.H.F. (2007). A transformação da noção de espaço público: a tendência à heterotopia no Largo da Carioca. Tese de Doutorado em Geografia (UFRJ). Rio de Janeiro: UFRJ.

\section{Notas}

i Para os fins deste artigo, não seguimos as distinções promovidas na área de museologia, no qual os museus são classificados a partir dos temas centrais de suas coleções (artes, história, ciência, arqueologia etc.). Os problemas observados e a gestão dos seus espaços apresentam mais semelhanças do que diferenças.

ii Chama atenção o fato de que a nota esteve disponível na internet apenas durante alguns dias e que foi retirada em poucos dias. Após o cancelamento da mostra 'Queermuseu', o Santander Cultural permaneceu fechado durante alguns dias e eliminou de suas bases digitais qualquer menção ao ocorrido. No entanto, seu conteúdo permanece acessível de modo indireto pela repercussão que causou, em jornais e em plataformas como o youtube e o facebook. Apesar da inexistência de um processo jurídico duradouro e da impossibilidade de censurar a mostra, a ameaça de boicote foi suficiente 
para o desmonte e para a absorção do prejuízo financeiro. O próprio museu fecha temporariamente e, quando reabre ao público em 2019, se localiza em outra parte da cidade, conhecida como Farol Santander.

iii Estamos realizando uma pesquisa, ainda em estágio inicial, para averiguar a situação funcional de diversos museus no Brasil. O quadro apresentado pelo MinC por intermédio da plataforma "Mapa da Cultura" transparece o registro de cerca de 3500 museus. No entanto, o número apresenta um conjunto de polêmicas, pois depende do registro dos próprios agentes museais e não realiza um censo periódico para avaliar as mudanças de situação funcional. Não há, por exemplo, diferenciação entre museus de ordem apenas digital daqueles que de fato possuem um espaço físico. Tampouco realiza distinção clara entre coleções ou exposições que se organizam pontualmente daquelas permanentes. A plataforma Mapa da Cultura também não informa sobre os museus desativados, em reforma ou com coleções incorporadas as de outros museus. Como resultado, o Mapa da Cultura expressa uma vitalidade em seu registro que não contempla a diversidade de situações dos museus brasileiros. Até o momento, recebemos cerca de 500 respostas, com registros de 15 museus desativados, 96 museus em reforma ou incorporados a outras instituições em consulta aos e-mails divulgados dentro da plataforma. Os únicos elementos comuns entre estes casos eram encontrados nas dificuldades financeiras, nos problemas de segurança e nos custos para conservação de suas coleções. 